\title{
GÊNEROS EM PROJETOS DIDÁTICOS: PROCESSOS DE (DES)LEGITIMAÇÃO NO DISCURSO DE LICENCIANDOS DO PROGRAMA INSTITUCIONAL DE BOLSAS DE INICIAÇÃO À DOCÊNCIA
}

\author{
Márcia Mendonça ${ }^{1}$
}

\begin{abstract}
RESUMO: Este artigo discute aspectos da seleção e legitimação de gêneros do discurso tomados como objeto de ensino na implementaçáo de projetos didáticos de língua portuguesa, com base em duas entrevistas semiestruturadas com bolsistas de iniciação à docência do Programa Institucional de Bolsas de Iniciação à Docência (PIBID) em Letras da Universidade Estadual de Campinas (UNICAMP). O intuito é gerar conhecimento situado acerca das práticas e dos saberes docentes no contexto do PIBID, a fim de problematizar as escolhas e apreciações feitas, à luz das demandas da formação universitária, que mobiliza princípios teóricos e pedagógicos específicos, e da escola, que tem suas próprias necessidades.
\end{abstract}

Palavras-chave: Gêneros do discurso. Projetos didáticos. Legitimação social. Formação inicial. PIBID.

\footnotetext{
*Agradeço à Coordenação de Aperfeiçoamento de Pessoal de Nível Superior (CAPES), o apoio financeiro ao subprojeto Letras do Programa Institucional de Bolsas de Iniciação à Docência (PIBID) da Universidade Estadual de Campinas (Unicamp).

${ }^{1}$ Universidade Estadual de Campinas, Instituto de Estudos da Linguagem - Campinas (SP), Brasil. E-mail: mendonca.mrs@gmail.com
}

DOI: $10.1590 / C C 0101-32622018183598$ 


\title{
Genres in didactic projects: processes of (des) \\ legitimation in the discourse of undergraduate scholarship recipients of the Institutional Program of Initiation Teaching Scholarships
}

\begin{abstract}
This article discusses aspects of the selection and legitimation of discourse genres, which are understood as teaching objects, in the implementation of Portuguese Language didactic projects. The corpus is comprised of two semi-structured interviews with undergraduate scholarship recipients of the Institutional Program of Initiation Teaching Scholarship (PIBID) - Language Arts at University of Campinas (UNICAMP). The aim is to generate knowledge about the teaching practices in the context of PIBID, in order to problematize the choices and appreciations made, in light of the demands of university education, which mobilize specific theoretical and pedagogical principles, and school education, with its own demands.
\end{abstract}

Keywords: Discourse genres. Didactic projects. Social legitimation. Undergraduate teacher education. PIBID.

\section{INTRODUÇÃO}

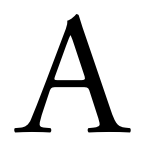

inda que a escola seja uma das instâncias de legitimaçáo do capital cultural (BOURDIEU \& PASSERON, 1964), este composto inclusive dos "conteúdos escolares", as práticas pedagógicas, performadas por sujeitos singulares, são parte das disputas inerentes aos processos de apropriação cultural. Nesse sentido, compreender as percepçôes dos professores em formação quanto ao papel e à relevância dos gêneros do discurso como objeto de ensino nos projetos didáticos pode contribuir para problematizar o trabalho com os gêneros na escola e os processos formativos que tomam corpo nas universidades e no âmbito de programas como o Programa Institucional de Bolsas de Iniciação à Docência (PIBID). 


\section{O SUBPROJETO LETRAS DO PIBID UNICAMP: PRINCÍPIOS E ORGANIZAÇÃO GERAL}

Como parte da política pública do PIBID, que privilegia a formação inicial de professores (BRASIL, 2008), o subprojeto Letras do PIBID da Universidade Estadual de Campinas (UNICAMP) (2014-2017) objetiva "aprimorar a formaçáo inicial dos licenciandos em Letras no que tange ao ensino de língua portuguesa e suas respectivas literaturas, tomando como foco central a diversidade linguístico-cultural" (BENTES; MENDONÇA; LOPES, 2014). O projeto está ancorado nos seguintes eixos temáticos:

- Registros de linguagem e diversidade cultural nas práticas escolares;

- Formação literária do leitor e formação docente;

- Gêneros do discurso, práticas escolares e formação docente.

A cada ano, podia-se eleger um tema detonador para os projetos nas escolas, com relevância social e formativa e que permita o diálogo entre os projetos. Nosso projeto incorporou bolsistas das licenciaturas em Pedagogia, Ciências Sociais, Geografia, História, Artes Visuais e Dança, com predominância de oriundos do curso de Letras. Essa equipe interdisciplinar elaborou e implementou projetos didáticos com foco na leitura e na escrita, tomadas como parte dos letramentos escolares das áreas de conhecimento.

O subprojeto organizava suas açóes em quatro etapas, que podiam se sobrepor e se intercambiar:

- Mapeamento do contexto escolar;

- Planejamento;

- Mediação pedagógica;

- $\quad$ Acompanhamento, registro e avaliação.

Conhecendo o perfil da comunidade escolar e das turmas, iniciava-se o planejamento para estabelecer, em negociação com supervisores e 
alunos, o perfil geral dos projetos (as expectativas de aprendizagem, o produto final, a seleção inicial de textos e a criação de atividades). Alguns projetos aproveitavam o que os professores já desenvolviam, e outros eram modelados e implementados paralelamente ao currículo em andamento.

Em 2016, a equipe atuou em quatro escolas municipais de Campinas (SP) e desenvolveu 12 projetos didáticos específicos no ensino fundamental II, que contemplaram a produção de gêneros escritos, orais e multimodais variados, em suportes e mídias diversos.

\section{GÊNEROS DO DISCURSO COMO OBJETO DE ENSINO: RETOMANDO A DISCUSSÃO}

Considerados como construçóes socioculturalmente situadas, os gêneros podem evidenciar, de maneira produtiva, as intersecçóes entre linguagem, historicidade e subjetividade (BAKHTIN, 2000), constituindo tanto modos de inserção dos sujeitos em práticas de letramento variadas quanto um poderoso instrumento para apropriação e ampliação de capacidades de linguagem no percurso escolar (SCHNEUWLY \& DOLZ, 1999), estas transversais aos diversos gêneros. Todos os projetos desenvolvidos no âmbito do PIBID Letras UNICAMP exploraram gêneros do discurso, com ênfases distintas no que se refere às dimensóes do gênero (tema, forma composicional, estilo, nos termos bakhtinianos) (BAKHTIN, 2000) e concernente às interfaces com as esferas discursivas de que se originam e nas quais se consolidam e se modificam, tanto no eixo da leitura quanto no da produção.

Quanto às forças que atuam na organização das práticas escolares de linguagem, Soares (2011) já mencionava a escolarização da literatura e de outras práticas de letramento como um processo inevitável que pode se dar num gradiente de maior ou menor adequação, segundo, por exemplo, a aproximação/o distanciamento entre as práticas sociais de referência e essas "mesmas" práticas escolarizadas — ensináveis, ensinadas e adquiridas (SCHNEUWLY \& DOLZ, 1999). A escolarização, portanto, opera modificaçóes nesses objetos, que passam a atender a finalidades intrínsecas à escola. 
Compreendo que a escola traz em si as contradiçóes e a diversidade intrínsecas da arena social e, dessa forma, não advogo a polarização entre o "fora" e o "dentro" da escola, pois esta e outras instituiçóes sociais são porosas e se influenciam mutuamente. Defendo que a familiarização com gêneros do discurso, desde que mantidos os laços com as esferas de ação humana em que são gerados e em que (re)existem, bem como as relaçóes de poder que se constituem nesses espaços sociais, aproximam os estudantes de múltiplos discursos e possibilitam a percepção das apreciaçóes valorativas (BAKHTIN, 2000) imprimidas aos enunciados, além da produção, por parte dos aprendizes, de suas próprias apreciaçóes na cadeia infinita de enunciados. Ao mesmo tempo, admito a especificidade do trabalho escolar que seleciona, se apropria de e modela os objetos de ensino com vistas à aprendizagem no âmbito da educação formal, geralmente de maneira sistemática. Vejo tais recortes como inerentes aos processos de escolarização, nos quais os professores são atores importantes, dado que as práticas docentes mobilizam e reconstituem ativamente os diversos saberes docentes: de formação profissional, disciplinares, curriculares e experienciais (TARDIF, 2005).

A apropriação dos gêneros no contexto das práticas escolares constitui, nesse sentido, parte do capital cultural (BOURDIEU \& PASSERON, 1964) valorizado nessa instância, o que é legitimado, em maior ou menor grau, em documentos curriculares - Parâmetros Curriculares Nacionais (PCN - BRASIL, 1997) e Orientaçóes Curriculares para o Ensino Médio (OCEM - BRASIL, 2006) - e em discursos de agentes educacionais. Conforme aponta Rojo (2008, p. 96), a didatização dos gêneros "vai colocar em confronto as formas do dialogismo próprias de cada gênero e de cada texto e as formas da recepção da palavra na escola”. Esses deslocamentos e confrontos são as refraçôes próprias das práticas pedagógicas, do fazer docente, que ressignifica cotidianamente o que vem a ser "ensinar gêneros", "ensinar com gêneros" e "ensinar por meio de gêneros".

\section{GÊNEROS DO DISCURSO NOS PROJETOS DIDÁTICOS DE 2016 DO PIBID LETRAS UNICAMP}

Ao longo dos últimos três anos de trabalho, os projetos implementados no PIBID têm se configurado como projetos didáticos (PDs) ${ }^{1}$ 
que oportunizam a participação dos alunos em práticas de letramento variadas, de maneira a mobilizar e ampliar capacidades de linguagem nos eixos da leitura/escuta e produção de texto por meio da exploração de gêneros do discurso. Sempre que pertinente, os projetos estiveram relacionados à temática eleita em cada ano letivo no âmbito do PIBID, o que influenciou a seleção de textos e gêneros, as atividades e o tipo de produto final ou atividade de culminância.

Considero que os projetos implementados no contexto do PIBID Letras UNICAMP têm se aproximado dos denominados "projetos de letramento" (KLEIMAN, 2000), por possibilitarem mobilizar a escrita com finalidades para além das escolares, pois tomam as práticas de leitura e de produção de texto como parte de um processo de ampliação de capacidades crítico-discursivas que extrapolam o "ler para aprender a ler" e "escrever para aprender a escrever", historicamente constituídos nas práticas escolares.

Por outro lado, nos contextos de implementação de projetos didáticos do PIBID, as escolhas dos gêneros são complexas e podem não se basear no interesse dos alunos, tal como se prevê nos projetos de letramento. Tanto podem ser mais diretamente influenciadas por uma demanda imediata do contexto escolar, como, ainda, responder a questóes mais gerais, tais como a abordagem de temas sociais relevantes (podendo ser do ponto de vista dos professores, da equipe do PIBID Letras ou dos alunos das escolas), a consideração de prescriçóes curriculares, o atendimento a necessidades de aprendizagem ou uma combinação desses fatores.

\section{OS DADOS}

Entre os projetos desenvolvidos em 2016, selecionamos o vlog literário para a análise, uma vez que ele congregava aspectos relevantes para problematizar a legitimação dos gêneros do discurso como objeto de ensino, tais como o trabalho com a esfera literária e com as interfaces entre linguagens e tecnologias, na perspectiva dos novos e multiletramentos. Os alunos da escola escolheriam um conto ou uma crônica e produziriam um vídeo para um vlog literário, um gênero mul- 
timodal que surgiu como parte das práticas de letramentos vernaculares (BARTON \& HAMILTON, 1998) de compartilhamento de vídeos com conteúdos variados na internet e comentários apreciativos a respeito. A produção do vlog implicava o uso de tecnologias e múltiplas linguagens em uma perspectiva plural, a dos multiletramentos (NEW LONDON GROUP, 1996).

O propósito essencial era explorar a leitura literária de fruição e a subjetividade dos alunos leitores. Eles deveriam avaliar o conto ou a crônica que haviam escolhido, remetendo-se ao enredo. Segundo os bolsistas, a ideia do projeto consistia em oportunizar aos alunos tanto o cultivo pelo prazer de ler textos literários, um aspecto considerado relevante pelos proponentes, quanto a escolha pessoal das obras de que mais gostaram, para comentá-las do seu ponto de vista. Os estudantes iriam selecionar os textos com base em uma coletânea criada pelos bolsistas, depois os discutiriam em grupo, para enfim escolher o texto a ser comentado no $v \log$. Seguiam-se as etapas de gravação, edição e publicação do $v \log$.

Os dados foram coletados por meio de duas entrevistas semiestruturadas com Sérgio e Carlos (nomes fictícios), bolsistas do projeto de produção do $v \log$ literário, que cursavam, respectivamente, o $2^{\circ}$ e o $4^{\mathrm{o}}$ ano de Letras. As entrevistas buscaram compreender como o projeto havia sido concebido pelos bolsistas e outros mediadores (supervisora e coordenadora) e as percepçóes deles acerca do trabalho com gêneros do discurso no desenvolvimento do das atividades.

\section{GÊNEROS NOS PROJETOS: PERTINÊNCIAS E RELEVÂNCIAS NA PERSPECTIVA DOS LICENCIANDOS}

O discurso dos bolsistas entrevistados apontou para fatores variados quanto à escolha e relevância dos gêneros no projeto, até mesmo quando comparavam mais de um gênero. Vejamos exemplos das principais categorias a que chegamos, após a análise das entrevistas, considerando que algumas delas se entrecruzam. 


\section{GÊNEROS, CURRÍCULO E APRENDIZAGENS EM LÍNGUA PORTUGUESA}

Os bolsistas da Iniciação à Docência (ID) destacaram a relevância do trabalho com certos gêneros do ponto de vista curricular, fosse quanto ao currículo prescrito, fosse quanto ao currículo efetivamente implementado. Sérgio considerou que a leitura de contos e crônicas é um dos passos para a formação do leitor literário, tarefa de longo prazo atribuída também à escola:

Então, um dos objetivos, que obviamente é um objetivo que não vai ser atingido agora, na medida que ele é um objetivo a ser atingido ao longo de anos, é desenvolver um pouquinho o prazer pela leitura. [...] Um dos outros objetivos é conseguir trabalhar um pouquinho que o aluno entenda que ele também pode falar sobre literatura (Sérgio, exemplo 1).

O bolsista salientou ainda o papel da escola na formação literária dos estudantes, como parte das amplas oportunidades formativas a que todos os brasileiros têm direito no percurso escolar. Os dois entrevistados mencionaram também a ampliação do repertório de leituras literárias a que os aprendizes são expostos ao longo da escolarização:

Entendo que, dado que na nossa cultura, a leitura literária ela não é cotidiana para todo mundo, e se a escola tem um mínimo de possibilidade de lidar com a realidade desigual do nosso país, talvez a escola seja um espaço em que a literatura pode ser trabalhada, uma vez que ela está restrita a classes muito específicas (Sérgio, exemplo 2).

Eles também podem falar de literatura, seja ela canônica, seja ela não canônica, Seja pra falar sobre Clarice Lispector, Mia Couto, Moacyr Scliar (Sérgio, exemplo 3).

Como a gente trabalhou com textos canônicos, eu acho que isso entra como repertório pra eles, vai ajudar nas leituras de texto literário ou nas leituras de textos em geral (Carlos, exemplo 4). 
Outros tópicos para aprendizagem previstos em orientaçóes curriculares foram também objeto de reflexão por parte dos bolsistas ID ao comentarem o trabalho com os gêneros selecionados para cada projeto. Entre esses tópicos, estavam a relação entre oralidade e escrita e o trabalho com o gênero multimodal $v \log$ :

Primeiramente ele é um texto oral, perdáo, ele é multimodal, mas tá no campo da oralidade, então isso é uma coisa que dá pra trabalhar, seja os alunos entenderem as diferenças possíveis entre oral e escrito, seja eles entenderem como construir textos orais de maneira coesa, como se aproveitar das coisas que a oralidade pode oferecer para tentar construir um texto coerente, coeso; seja eles entenderem como eles vão variar entre uma fala pública e uma fala privada, ainda que a fala pública, no caso do vlog, seja informal, mas que provavelmente vai implicar em diferenças (Sérgio, exemplo 5).

O trabalho com esses gêneros multimodais também tem muito a oferecer na medida em que eles vão trabalhar com textos que tenham um encontro de diversas linguagens e eles vão ter que pensar sobre imagens, eles vão ter que pensar, por exemplo, em trilha sonora, em elementos paratextuais desses textos multimodais, que às vezes a gente nem pensa que tem tanta coisa (Sérgio, exemplo 6).

A intersecção com os gêneros tomados como objeto de ensino nos documentos curriculares brasileiros sobre ensino de língua portuguesa se concretizou de diferentes maneiras e ênfases, segundo o que disseram os bolsistas. Isso indicia, como já apontado, um processo heterogêneo de apropriação do ensino de gêneros pelos professores em formação.

\section{GÊNEROS ESCOLARES AUXILIARES DA APRENDIZAGEM}

Ainda ligado ao currículo, um dos dados que se destaca nas entrevistas dos bolsistas é o papel dos gêneros usados para alavancar aprendizagens, principalmente como ferramenta de planejamento dos 
alunos. No projeto do $v \log$, foi solicitado que os estudantes fizessem um roteiro dos comentários sobre as obras, antes da filmagem. Para os bolsistas, o roteiro foi pouco importante e o adjetivo escolar parece ser negativo:

Pro ensino de [língua portuguesa] LP, não sei em que medida ele é um grande gênero, a gente escolheu ele mais, na minha opinião, pra dar andamento ao projeto, pra tentar ajudar os alunos na empreitada de gravar o vlog (Carlos, exemplo 7).

Um roteiro escrito, uma espécie de gênero... escolar aí, talvez, na medida em que ele é um gênero que pouco circula, mas seria a ideia de tanto ajudar os alunos a encadear bem as ideias no papel para depois, um segundo momento de gravação, e também pra uma prática de escrita. $\mathrm{O}$ roteiro acabou sendo pouco usado. A gente acabou fazendo poucos roteiros em relação ao número de obras comentadas. Por conta do pouco tempo, a gente teve de encurtar (Sérgio, exemplo 8).

Uma vez que a fala no vlog não é calcada em um texto escrito, ou seja, não se lê para falar no momento da gravação, esse gênero foi incluído no projeto para ajudar os estudantes tanto a prever o que seria dito e, portanto, a realizar uma fala planejada, com algum grau de monitoramento; quanto para desenvolver capacidades de escrita. Entretanto, a relevância do gênero roteiro no projeto é minimizada pelos bolsistas, talvez por ser enquadrado como um gênero escolar com supostamente pouca circulação social fora dessa esfera, ou por ter restado pouco tempo para sua exploração.

A propósito dos gêneros escolares, Schneuwly e Dolz (1999, p. 8) afirmam que são "autênticos produtos culturais da escola elaborados como instrumentos para desenvolver e avaliar progressivamente e sistematicamente as capacidades de escrita dos alunos". Vale ressalvar que os roteiros e outros gêneros de apoio a planejamento de açóes - esquemas, resumos, sínteses, pautas de reuniáo etc. — são ainda bastante frequentes em contextos extraescolares, especialmente os de trabalho. 
A menção ao roteiro para produzir o vlog como gênero escolar pode ter relação com o fato de que boa parte do discurso dos vloggers náo parece planejado: os booktubers (ou vloggers especializados em literatura) falam como se conversassem informalmente com os internautas sobre obras e autores, aspecto salientado por alguns desses comentaristas como o diferencial que atrai o público mais jovem, na comparação com a leitura de resenhas escritas, também acessíveis na web. Tal informalidade característica pode ter levado os licenciandos a considerarem a produção do roteiro escrito como uma etapa dispensável antes da produçáo dos vídeos, porque mais endógena à escola. Dessa forma, o roteiro foi visto pelos bolsistas do projeto do $v \log$ como um gênero de importância secundária naquela situação, tanto por seu caráter escolar quanto pela ineficácia no auxílio à elaboração dos comentários das obras, o que justificaria sua inserção no projeto. Nessa perspectiva, os roteiros não se encaixariam no conjunto dos gêneros "ensináveis", previstos em currículo, a despeito do que indicam os PCN de língua portuguesa quanto ao planejamento de falas públicas: "Espera-se que o aluno produza textos orais, planejando-os previamente em função dos objetivos estabelecidos, com apoio da linguagem escrita e de recursos gráficos, quando for o caso" (BRASIL, 1997, p. 96). Vejamos:

Com certeza, o roteiro ficaria para trás, porque foi algo que deu um andamento para alguns alunos que tavam inseguros, mas que no todo não é um grande gênero pra ser ensinado na aula de português (Sérgio, exemplo 9).

Vale destacar a percepção de Carlos acerca da relevância do gênero $v \log$ e dos demais explorados no projeto para o currículo de português:

Acho que da forma como a gente trabalhou eles estáo por fora [do currículo]. Dessa forma de o aluno chegar ao livro, escolher o livro, poder falar. Acho que tá um pouco por fora.

A gente não chegou a trabalhar com análise linguística em nenhum momento. Talvez, em relação à interpretação de texto, isso ficasse dentro. Talvez, como não se configura muito como sequência didática, acho que talvez isso fica 
um pouco fora, porque eles acabam produzindo um gênero que não é aqueles que eles estáo lendo. Mas era uma grande questão pra mim também (Carlos, exemplo 10).

Percebe-se que o licenciando póe em xeque a legitimidade do trabalho realizado no projeto com os gêneros em função da distância em relação a princípios teórico-metodológicos estudados no âmbito da graduação em Letras da UNICAMP (saberes disciplinares). O primeiro deles é o modelo das sequências didáticas (SDs) de Genebra (DOLZ; NOVERRAZ; SCHNEUWLY, 2004), voltadas para a produção textual. De acordo com essa abordagem, um conjunto de atividades inter-relacionadas é planejado de modo que o gênero lido é modelo do gênero que será produzido e se tomam como objeto de ensino algumas das dimensóes ensináveis desse gênero, pretendendo-se a sua progressiva apropriação por parte do aprendiz. O outro conjunto de princípios teórico-metodológicos refere-se às práticas de análise linguística, conforme as quais a reflexão sobre o funcionamento dos recursos e das estratégias linguístico-discursivos deve visar à aprendizagem para o uso e pelo uso - que são típicos de certos gêneros e que estão presentes em textos (MENDONÇA, 2006).

Carlos, ao considerar que a SD seria a única forma de organização do trabalho pedagógico legitimada no currículo de língua portuguesa, pôs em segundo plano outras possibilidades de encaminhar a produção de textos na escola, especialmente tendo em vista fatores como tempo e perfil da turma. O caminho adotado no projeto foi priorizar a leitura dos contos e crônicas e a troca de experiências e percepçóes sobre leitura, e não investir tempo na modelização do vlog. Do mesmo modo, uma eventual menor ênfase nos aspectos linguísticos talvez se justifique pelos objetivos priorizados, tais como possibilitar a leitura de fruição, ampliar o repertório literário, permitir a expressão de um ponto de vista subjetivo acerca de uma obra literária e divulgar essa perspectiva para um público amplo, entre outros. Tal ordem de critérios de validação não estava contida nos saberes disciplinares, mas se construiu nos saberes em ação, balizada pela coerência pragmática dos docentes (CHARTIER, 2007), que não equivale aos saberes das disciplinas de referência. 


\section{GÊNEROS ADEQUADOS AO TEMPO PEDAGÓGICO OU AO PERFIL DA TURMA}

O tempo pedagógico foi outro fator que contribuiu para a seleção dos gêneros:

Em termos de gêneros específicos, o conto e a crônica são escolhidos justamente pela leitura breve, que pode ser feita em vários pedaços de uma mesma aula. Eles acabam sendo privilegiados por sua [curta] extensão (Sérgio, exemplo 11).

Um aluno, faltando numa aula, ia prejudicar a leitura dele numa outra atividade. Entáo pegar textos curtos a gente achou que ia ser mais fácil pra funcionar na escola. A gente adoraria trabalhar com textos longos com eles, poder contar que eles fossem ler os textos em casa, mas a gente, já conversando com a professora, sabia de antemão que a tarefa de casa era coisa que náo funciona com eles, sabia a coisa das faltas também. Se é para trabalhar literatura, que seja algo que caiba em uma aula (Carlos, exemplo 12).

Carlos ainda justifica por que escolheram contos e crônicas, e não poemas: com base no perfil da turma e na sua experiência docente no PIBID no ano anterior, quando percebeu dificuldades enfrentadas pelos alunos ao lerem textos poéticos:

E por que náo poesia, que também seria coisa curta, em geral? A gente trabalhou com poesia no ano anterior e a gente achou mais complicado, a gente achou que a distância pra poesia [falta de familiaridade dos alunos] é maior que pra prosa (Carlos, exemplo 13).

\section{GÊNEROS CAPAZES DE ENGAJAR OS ESTUDANTES NO PROJETO}

Em todos os projetos, o engajamento dos estudantes era uma das preocupaçóes dos bolsistas e dos supervisores, para garantir o anda- 
mento das atividades, que previam a participação ativa dos discentes. O vlog cumpriria esse papel motivador:

Bem, o vlog é fundamental, porque ele é o produto final [...], é meio que o motivador para todas as atividades. A nossa ideia era trabalhar a leitura de literatura prazerosa, e o vlog entra com o papel de motivar o primeiro processo, que é a leitura literária. [...] A leitura literária e o texto literário, esses gêneros literários são o objetivo. $\mathrm{O}$ objetivo é que eles se familiarizem com esses gêneros, que se sintam capazes se lê-los de entendê-los, de curti-los e de falar sobre eles, principalmente. [...] Em relaçáo à motivação, era como pegar uma coisa que em geral eles acham que vai ser chato e tentar fazer essa atividade [...] mais prazerosa (Carlos, exemplo 14).

O bolsista faz uma comparação implícita entre o vlog e outros gêneros, ao considerá-lo "menos chato". Isso talvez tenha ocorrido pela convergência de novos e multiletramentos próprios das culturas juvenis nos vlogs, que comentaremos adiante.

Tendo em vista ainda a falta de prática e de autoconfiança dos alunos para falar em público acerca de literatura (e talvez de outros temas), Carlos comentou:

Eu acho que talvez um pouco de confiança de que falar de literatura é possível e pode ser gostoso pode ser uma experiência prazerosa de alguma forma, que pode ser pessoal (Carlos, exemplo 15).

\section{GÊNEROS E SUBJETIVIDADES}

Outro eixo que ganhou importância nos projetos foi o das práticas de letramento como oportunidade para expressão de subjetividades e identidades sociais, pois o $v \log$ ensejava o posicionamento dos alunos 
de uma perspectiva bastante pessoal, permitindo ainda a percepção de pontos de vista comuns entre os estudantes.

Os bolsistas do projeto do $v \log$ consideraram importante a manifestação das subjetividades dos estudantes, como leitores de literatura, que podem gostar do que leem e apreciar a oportunidade de falar dessas leituras de seu ponto de vista, como verificado no trecho anterior da fala de Carlos e ainda no próximo:

A ideia era que a gente trabalhasse com leitura de texto literário e que a gente desse uma oportunidade pra os alunos de falar sobre as leituras deles. Entáo a gente queria criar um espaço em que eles pudessem fazer as leituras em grupo, conversar sobre essas leituras, pensar juntos sobre elas e depois que eles conversassem sobre elas pudessem unir a opiniáo deles em um texto oral e gravar um vídeo sobre eles (Carlos, exemplo 16).

\section{GÊNEROS E NOVOS E MULTILETRAMENTOS}

O trabalho com múltiplas linguagens envolvidas em dada prática de letramento e com tecnologias digitais de informação e comunicação (TDICs) foi a tônica dos projetos de vlog. Essa característica aparece, de forma mais ou menos explícita, na justificativa para a escolha desses gêneros. Segundo Sérgio, os vlogs literários são

Vídeos que atualmente são bastante feitos por jovens geralmente para falar sobre best-sellers em que as pessoas relatam as experiências de leitura, fazem um breve resumo do enredo, dizem questóes relativas à forma e apreciaçáo da obra, enfim. [...] O grande gênero, a menina dos olhos desse projeto é o vlog literário, um gênero multimodal, que, como eu já disse, tem um leque de temas possíveis e de valoraçóes possíveis sobre o tema, estilo, estrutura composicional (Sérgio, exemplo 17). 
A produção do vlog propicia aos estudantes produzir conteúdo multimodal (em vídeo) disponibilizado na web, com apreciaçóes a respeito das obras literárias e de seus autores, tal como fazem legióes de jovens contemporâneos, em vlogs, blogs, posts, redes sociais etc. Isso contribui para a familiarização dos discentes com eventos de letramentos em que tais apreciaçóes explícitas são constitutivas e, portanto, centrais para a ampliação das capacidades verbais exigidas nessas ocasióes. Sendo a leitura literária a questão primordial, o objetivo era aproximar os estudantes desse universo, conforme fala anterior de Carlos.

Outro objetivo do projeto foi que os alunos soubessem que

Podem falar sobre essas obras para um público amplo, editar isso e colocar isso para circular. A gente quer trabalhar com eles e trabalhou com eles a noção de que eles sim podem falar sobre isso (Sérgio, exemplo 18; cf. exemplo 3).

Os vlogs são parte das práticas de letramento digitais permeadas pela perspectiva dos novos letramentos no âmbito das práticas de leitura e escrita da web 2.0 (O'REILLY, 2005), principalmente quanto à expertise distribuída: não especialistas falam a não especialistas, ou seja, jovens que gostam de ler falam para outros jovens sobre obras que leram. Esses jovens passam a ocupar esse espaço discursivo, antes restrito a experts — críticos literários —, e a ser legitimados não por instituiçóes que atestem a pertinência do seu capital cultural, como a universidade e a própria crítica literária, mas pela comunidade de usuários, que cria e recria padrôes de legitimação tendo em vista a lógica do conhecimento distribuído, compartilhado, numa mentalidade típica da web 2.0.

\section{CONSIDERAÇÕES FINAIS}

No eixo da leitura, as razóes para escolher os gêneros permanecem variadas: pertinência para o tema do projeto; interface com culturas juvenis, supostamente próximas dos alunos das classes; adequação ao tempo pedagógico ou ao perfil da turma; possibilidade de alavancar aprendiza- 
gens quanto à produção do gênero em foco; impacto na aprendizagem de outras habilidades de linguagem previstas no currículo etc. Ao lado de critérios mais legitimados pela instância universitária de formação (relevância fundada em teorias consolidadas) ou pela instituição escolar (previsão no currículo escolar, adequação ao perfil da turma e da escola), outros fatores influenciaram a escolha dos gêneros do discurso nos projetos.

Do ponto de vista dos pibidianos, professores em formação inicial imersos em uma prática docente supervisionada de maneira colaborativa, as decisóes pedagógicas inerentes ao exercício profissional já começam a se delinear mais complexas e multifacetadas que as prescrições curriculares ou as teorias estudadas na universidade. Os gêneros do discurso, nesse contexto, passam a integrar os projetos não só (e nem sempre) por causa da didática dos gêneros (genebrina, australiana ou americana), cuja (re)apropriação no contexto da escola no Brasil tem traços singulares, ou por conta da sua pertinência curricular, ou por seu enquadramento no paradigma dos novos e multiletramentos, sendo estes um dos componentes do currículo da licenciatura que cursam.

Para Chartier (2007), os professores agem em nome de uma coerência pragmática que não equivale às epistemologias dos saberes disciplinares e que se funda na experiência docente e nos saberes da ação. Assim, mais que saberes de formação profissional, disciplinares ou curriculares, são mobilizados/(re)elaborados saberes experienciais (TARDIF, 2005) acerca dos gêneros a selecionar, dos objetivos e das razóes para isso. Os saberes experienciais referentes a esse processo de seleção dos gêneros tomados como objeto de ensino resultam da atividade laboral dos professores, dado que são por eles produzidos na vivência de situações específicas ligadas ao espaço escolar e às relaçóes estabelecidas com os demais membros da comunidade escolar. No caso do projeto analisado, conciliar demandas escolares, tempo exíguo para as atividades, potencial de motivação dos alunos e relevância para a aprendizagem escolar na disciplina língua portuguesa foram as principais frentes com as quais os bolsistas ID tiveram de lidar.

Concordamos com Tardif (2005, p. 24-25), para quem é preciso trazer à luz "tensóes internas que surgem da atividade dos professores, as quais decorrem, em grande parte, da presença simultânea de modelos heterogêneos ou contraditórios orientando a organização do seu trabalho 
na escola". Tal heterogeneidade, se tomada como constituinte do cotidiano profissional dos docentes, deixa de ser um problema a ser resolvido e passa a ser uma característica com a qual é preciso lidar, todos os dias, encontrando as respostas possíveis e que poderão ser legitimadas ou não, ao longo do tempo, pelo conjunto de atores da comunidade escolar e pela sociedade como um todo.

Como derivação possível das análises empreendidas, defendemos a necessidade de se pensar políticas educacionais mais democráticas, que considerem os agentes pedagógicos e as culturas escolares locais, mesmo quanto à incorporação da proposta de trabalho com gêneros do discurso como objeto de ensino. Dessa maneira, a incorporação de um objeto de ensino - seja ele os gêneros do discurso, seja qualquer outro objeto de conhecimento — poderá passar por um processo de legitimação social mais plural. Passos importantes são admitir e explicitar as refraçóes que incidem sobre esse objeto de ensino, constitutivas do processo de legitimação social, sempre resultantes das múltiplas reconfiguraçóes e apreciaçóes de valor realizadas, no caso em estudo, pelos agentes e pelas instâncias educacionais responsáveis pelo ensino de língua portuguesa. Nesse sentido, os objetos de ensino das aulas de português, incluindo os gêneros do discurso, não são, mas podem passar a ser necessários, pertinentes, relevantes às aprendizagens dos alunos e à sua formação como sujeitos da linguagem.

\section{REFERÊNCIAS}

BAKHTIN, M. Os gêneros do discurso. In: Estética da criação verbal. 3. ed. Sáo Paulo: Martins Fontes, 2000. p. 277-326.

BARTON, D.; HAMILTON, M. Local literacies. Londres e Nova York: Routledge, 1998.

BENTES, A.; MENDONÇA, M.; LOPES, M. Diversidade linguisticocultural, práticas escolares e formação inicial em Letras: subprojeto PIBID Letras UNICAMP. Campinas: Unicamp, 2014.

BOURDIEU, P.; PASSERON, J.C. Les héritiers: les étudiants et la culture. Paris: Les Éditions de Minuit, 1964. 
BRASIL. Coordenação de Aperfeiçoamento de Pessoal de Ensino Superior. PIBID - Programa Institucional de Bolsas de Iniciação à Docência: objetivos do programa. Brasil: Ministério da Educação, 2008. Disponível em: < http://www. capes.gov.br/educacao-basica/capespibid/pibid>. Acesso em: 18 jan. 2017.

. Secretaria de Educaçáo Fundamental. Parâmetros curriculares nacionais: língua portuguesa. Brasília: Ministério da Educação/Secretaria de Educação Fundamental, 1997.

- Orientaçóes curriculares para o ensino médio: linguagens, códigos e suas tecnologias. Brasília: Ministério da Educação/Secretaria de Educação Fundamental, 2006.

CHARTIER, A.M. A ação docente: entre saberes práticos e saberes teóricos. Práticas de leitura e escrita: história e atualidade. Tradução de Flávia Sarti e Teresa Van Acker. Belo Horizonte: Ceale; Autêntica, 2007. p. 185-207.

DOLZ, J.; NOVERRAZ, M.; SCHNEUWLY, B. Sequências didáticas para o oral e a escrita: apresentação de um procedimento. In: DOLZ, J.; SCHNEUWLY, B. (Orgs.). Gêneros orais e escritos na escola. Campinas: Mercado de Letras, 2004. p. 95-128.

KLEIMAN, A.B. O processo de aculturação pela escrita: ensino da forma ou aprendizagem da função? In: KLEIMAN, A.B.; SIGNORINI, I. (Orgs.). O ensino e a formação do professor: alfabetização de jovens e adultos. Porto Alegre: Artmed, 2000. p. 223-243.

MENDONÇA, M. Análise linguística no ensino médio: um novo olhar, um outro objeto. In: BUNZEN, C.; MENDONÇA, M. (Orgs.). Português no ensino médio e formação do professor. São Paulo: Parábola, 2006. p. 199-226.

Projetos de letramento, sequências didáticas e ensino de gêneros no PIBID Letras Unicamp: lógica das práticas e formação de professores. In: PRODÓCIMO, E.; PRADO, G.V.T.; AYOUB, E. (Orgs.). PIBID-UNICAMP: conhecimentos e saberes produzidos na práxis educativa. Campinas: Unicamp, 2016. v. 5. p. 73-89.

NEW LONDON GROUP. A pedagogy of multiliteracies: designing social futures. Harvard Educational Review, v. 66, p. 60-92, 1996.

O'REILLY, T. What is web 2.0: design patterns and business models for the next generation of software. 2005.

ROJO, R. Gêneros de discurso/texto como objeto de ensino de línguas: um retorno ao trivium? In: SIGNORINI, I. (Org.). [Re]discutir texto, gênero e discurso. São Paulo: Parábola, 2008. p. 73-108. 
SCHNEUWLY, B.; DOLZ, J. Os gêneros escolares: das práticas de linguagem aos objetos de ensino. Revista Brasileira de Educação, n. 11, p. 5-16, 1999.

SOARES, M. A escolarização da literatura infantil e juvenil. In: EVANGELISTA, A.A.M.; BRANDÃO, H.M.B.; MACHADO, M.Z.V. (Orgs.). Escolarização da leitura literária. 2. ed. Belo Horizonte: Autêntica, 2011. p. 17-48.

TARDIF, M. O trabalho docente: elementos para uma teoria da docência como profissão de interações humanas. Petrópolis: Vozes, 2005.

\section{NOTA}

1. Postulo aqui a denominaçáo projetos didáticos (PDs) (nesse caso, de língua portuguesa) diferentemente da denominação usada em trabalho anterior (MENDONÇA, 2016) — projetos de letramento —, já que podem partir ou não de problemas emergentes na comunidade escolar e, ainda que orientados na perspectiva dos letramentos, se distinguem dos projetos de letramento na acepçáo de Kleiman (2000).

Recebido em 02 de agosto de 2017.

Aceito em 23 de março de 2018. 